Association for Information Systems

AIS Electronic Library (AISeL)

AMCIS 2003 Proceedings

Americas Conference on Information Systems

(AMCIS)

December 2003

\title{
The Consumer Online Purchase Decision: A Model of Consideration Set Formation and Buyer Conversion Rate Across Market Leaders and Market Followers
}

Neveen Farag

University of Michigan

Michael Smith

Carnegie Mellon University

Mayuram Krishnan

University of Michigan

Follow this and additional works at: http://aisel.aisnet.org/amcis2003

\section{Recommended Citation}

Farag, Neveen; Smith, Michael; and Krishnan, Mayuram, "The Consumer Online Purchase Decision: A Model of Consideration Set Formation and Buyer Conversion Rate Across Market Leaders and Market Followers" (2003). AMCIS 2003 Proceedings. 37.

http://aisel.aisnet.org/amcis2003/37

This material is brought to you by the Americas Conference on Information Systems (AMCIS) at AIS Electronic Library (AISeL). It has been accepted for inclusion in AMCIS 2003 Proceedings by an authorized administrator of AIS Electronic Library (AISeL). For more information, please contact elibrary@aisnet.org. 


\title{
The Consumer Online Purchase Decision: A Model OF CONSIDERATION SET FORMATION AND BUYER CONVERSION RATE ACROSS MARKET LEADERS AND MARKET FOLLOWERS
}

\author{
Neveen I. Farag \\ Business School \\ University of Michigan \\ nfarag@umich.edu
}

\author{
Michael D. Smith \\ Heinz School of Public Policy \& Management \\ Carnegie Mellon University \\ mjshaw@uiuc.edu
}

\author{
M. S. Krishnan \\ Business School \\ University of Michigan \\ nfarag@umich.edu
}

\begin{abstract}
The ease of customer search and therefore comparison shopping online has received a lot of attention. While there is sufficient empirical evidence that the expected result of bertrand price competition does not necessarily occur, firms have still attempted to minimize search across other sites. For example, firms have tried to prohibit information gathering "spiders" from scanning their web pages. On the other hand, some firms have taken the opposite strategy, and have chosen to show competing firm options on their site as a direct comparison. In this study, we examine the formation and effect of consumser search sets, or "consideration sets" on the consumer purchase decision. In addition, we contrast the differing effects of consideration sets on market leaders and market followers. In so doing, we find that while searching across market leaders is not detrimental for market followers, searching across market followers is somewhat detrimental for market leaders. This result suggests that strong market leaders should increasingly employ online service, such as personalization, in an attempt to increase loyalty and decrease search.
\end{abstract}

Keywords: Consumer search, consideration sets, online consumer behavior, search costs, online service

\section{Introduction}

The ease of customer search and therefore comparison shopping online was supposed to be the death of many online retailers. However, there is sufficient empirical evidence that the expected result of bertrand price competition does not necessarily occur. Despite such evidence that consumers do not necessarily buy from the cheapest priced retailers, firms have still attempted to minimize search across other sites. For example, firms have tried to prohibit information gathering "spiders" from scanning their web pages. On the other hand, some firms have taken the opposite strategy, and have chosen to show competing firm options on their site as a direct comparison. In this study, we examine the formation and effect of consumer search sets, or "consideration sets" on the consumer purchase decision. In so doing, we contrast the differing effects of consideration sets on market leaders and market followers. The results of our analysis shed new light on whether Amazon.com should really list itself on price comparison web sites, and whether smaller firms, such as overstock.com, should really display a direct comparison of their competitors on their webpage, as some have in the past. 


\section{Prior Literature}

Prior literature has suggested that for consumers, the main attraction of interactive electronic retailing is a reduction in search costs for products and product-related information (Alba et al. 1997). On the firm side, the fear is one of classic Bertrand price competition, brought about by increased price competition (Anders 1998, 1999; Economist 1999). As a result, firms have attempted to block their site from online price comparison sites in order to increase price search costs (Bakos 1997; Pazgal and Vulcan 1998; Quick, 1998). However, empirical evidence suggests that even when consumers use price comparison websites, they do not always buy products from the lowest priced retailer. In an experimental study of wine online, Lynch and Ariely (2000) found that ease of cross-firm price comparison only increased consumer price sensitivity for wines common to many stores; however, for unique wines, cross-store comparison had no effect on price sensitivity. In addition, in the case of one comparison shopper web site, EvenBetter.com, Amazon.com had a $\$ 1.85$ price premium over unbranded retailers, and a $\$ 1.13$ markup over Barnes \&Noble, yet they still accounted for a large percentage of purchases (Smith and Brynjolfsson, 2001). Thus, despite consumers having easily accessible search options, they do not always chose to buy from the lowest price retailer. This result is in accordance with Fader and Hardie (1999), who show that consumers implicitly have a favorite firm, as well as Johnson, Bellman, and Lohse (2002) who show that sites with fast learning curves are associated with higher rates of purchase. These results suggest that consumers may use searching only to gather information, but they then buy from the preferred firm. Such implicit loyalty is potentially due to consumers preferring the shopping experience provided by the firm (Farag and Van Alstyne, 2002).

Firms attempt to increase consumer conversion rate through increased consumer loyalty. Firms utilize various online service mechanisms, including personalization, interaction, and information, in an attempt to increase loyalty (Farag and Krishnan 2002a), and thereby maximize consumer benefits of shopping at their site. However, there are several negative by-products that can come from implementation of online services. Included as potential negatives of the online experience are: poor ease of use (Hoffman et al. 1995), information overload (Smith, Bailey, Brynjolfsson 1999, Iyengar and Lepper 2000), and abundant online advertising (Dewan, Freimer, and Zhang 2001, McLaughlin 2002). We attempt to assess the impact of these negative online experience factors, as well as consumer searching behavior, on consideration set formation, as well as online conversion rate.

\section{Theoretical Model}

The decision to buy a product online often leads consumers to a state of heightened awareness about firms offering the product category the consumer is searching within, as well as about the products themselves and their attributes. Buyers may therefore undertake a process of active search. A great amount of prior research, starting with Howard and Sheth (1969) has examined consumer consideration set formation. When choosing to make a purchase, consumers classically use a 2-stage process. First, they screen the set of all possible brands to a relevant set called a consideration set (Alba and Chattopadhyay, 1985). They then make purchase/consumption decision from brands in the consideration set (Howard and Sheth, 1969). The notion of a consideration set is that consumers have either limited information-processing ability or limited information acquisition ability (Manrai and Andrews 1998). There has been a great deal of research on the details of this process; for this paper, we are most concerned with factors that effect the formation of an online consideration set, as well as how the size of the consideration set is associated with the consumer decision to purchase, as well as consumer conversion rate.

The theoretical construct of a consideration set is the number of online retailers that a consumer visits when making a purchase. Empirically, however, several definitions of evoked sets, relevant sets, and consideration sets have been used (Alba and Chattopadhyay, 1985; Howard and Sheth, 1969; Silk and Urban, 1978; for a comparison see Brown and Wildt, 1987). The concept behind these empirical definitions is consistent with a number of theories and results in behavioral science. For example, Miller (1975) reports that humans have limited ability to process and store information; similarly, Wright (1975) argued that consumers attempt to simplify their decision environment. Likewise in Economics, Stigler (1961) introduced the concept of search costs and showed that the rational consumer would not search all brands in the market. Nelson(1970) later noted that some goods, namely experience goods, couldn't be evaluated without consumption. In Marketing, Belonax and Mittlestaedt (1978) show that larger consumer evaluations costs lead to smaller consideration sets. Lastly in transportation science, researchers have examined consumers' adaptation of their searching over time (Meyer, 1979; Richardson, 1982). The focus of this study is limited to which online firms consumers include in their choice sets, and do they chose to buy from those online firms or not, and if they do, how often do they purchase.

The framework used in this paper is an extension of Payne (1982) and Hauser and Wernerfelt (1990). Payne calls his perspective the cost/benefit framework; it is a theoretical framework that stipulates that consumers make decisions after they weigh the effort 
(cost) and accuracy (benefit) of the decision rule. Hauser and Wernerfelt (1990) extend Payne's framework by postulating that the rational explanation of a consumer's action will be discernable at the aggregate level.

\section{The Utility of a The Consumer}

Consumers have a basic utility function when shopping online of the form shown in equation 1.1 , where $u_{p}$ is the utility associated with the product, $u_{e x}$ is the utility associated with the shopping experience, $c_{e x}$ is the disutility of the experience, and therefore the cost of the experience to the consumer, and $p_{p}$ is the price of the product.

$$
U=u_{p}+u_{e x}-c_{e x}-p_{p}
$$

Thus for consumers to be willing to purchase a product from a given site, their total utility must be greater than 0 , as shown in equation 1.2. We see from this, that what a consumer is willing to pay for a product is shaped somewhat by their utility of the shopping experience.

$$
u_{p}+u_{e x}-c_{e x}-p_{p}
$$

In this paper we focus on the utility and costs associated with the shopping experience, thus the middle two elements of utility function, $u_{e x}-c_{e x}$, and their sub-elements. Before undergoing the online shopping experience of a firm, consumers have a lack of a clear understanding of what to expect for their shopping experience. Thus, we define their $a$ priori utility, $\tilde{u}_{j}^{\prime}$ as a random variable, indicating what the consumer believes his/her shopping experience utility will be, where $j$ represents the firm, and we assume a fixed product being shopped for.

Let $\sigma_{u}^{2}$ be the variance of the pre-experience utility across all firms, over the same product. After evaluation, the consumer experiences some features of the online firm, and is then able to update his/her beliefs about utility. Let $a_{j}$ be the value of the consumer's utility due to experience, such that:

$$
a_{j}=\tilde{u}_{j}-\tilde{u}_{j}
$$

where $\tilde{u}_{j}$ denotes the post-experience utility. Note that $a_{j}$ can be positive, negative, or of zero value depending upon whether consumer utility increases, decreases, or remains the same after they have partaken in the online shopping experience.

On the consumer cost side, consumers incur a consideration cost, $s_{j}$ of evaluating firms for inclusion in the consideration set. Mehta et al. (2003) previously used the notion of a consideration cost to examine offline consideration set formation. Consumer consideration cost in our setting can be thought of as the cost of finding different firms to visit and evaluate. This cost includes thinking costs, information search costs, and opportunity costs of visiting various sites (Schmalansee, 1982). The second cost that comes into play is the disutility experience upon visiting a site cost, $d_{j}$. Various factors may come into play in the disutility of a shopping experience, such as advertising encountered, firm information offered, and ease of use of the shopping experience. It has been suggested in prior work to think of $s_{j}$ as the information gathering cost, and $d_{j}$ as the information processing cost (Hauser and Wernerfelt, 1990).

Since we are interested in understanding how consumer consideration sets are associated with online consumer conversion rate, we start by focusing on the particular purchase decision for a consumer who visits $n$ online firms. Thus, the expected utility of choosing to purchase from one of the firms visited, and therefore in the consideration set, is the expected value of the maximum of the individual consumer post-experience utilities minus the cost of considering the various online firms, as shown in equation 1.4 .

$$
E\left[\max \left(\widetilde{u}_{1}, \widetilde{u}_{2}, \ldots, \widetilde{u}_{n}\right)\right]-\left(\sum_{j=1}^{n} s_{j}+\sum_{j=1}^{n} d_{j}\right)
$$


We assume all visits take place before purchase, that the underlying utility function is the same across all the firms, and that the cost of considering $n$ firms to purchase from is the sum of the cost of considering each firm. Thus, we assume independence among online firms, meaning that the cost of considering one firm does not affect the cost of considering another online firm.

Consistent with prior literature on consumer brand and purchase decisions (Howard and Sheth, 1969), we split the online consumer conversion process into two decisions, to visit a set of firms, and to purchase from a given firm. The decision to visit a site entails a cost trade-off between the cost of experiencing the "negative" or non-favorable features of the site, and the benefits of including the firm in the consideration set for all subsequent purchases. We choose to examine the static decisions of how many firms a consumer puts into their consideration set, and whether or not consumers purchase from firms within their consideration sets. While it would be interesting in future work to examine the sequential process of consumer evaluation and purchase decision over time, data limitations keep us from doing so in this model.

Our theory so far has examined how consumers decide to visit online firms, and then whether they decide to purchase from them or not. Another element of the theory is what features firms implement to affect how consumers form beliefs about various online experiences. A firm can indeed influence the means and variances of the perceived utility, before $\left(\tilde{u}_{j}^{\prime}\right)$, and after $\left(\tilde{u}_{j}\right)$, a consumer partakes in its shopping experience by providing information or increasing the ease of use of a site. The firm can also potentially alter the evaluative consideration cost, $s_{j}$, and the disutility of the shopping experience, $d_{j}$ of the consumer.

Another element to consider is advertising. Advertising can increase the perceived utility of a shopping experience prior to purchase, $\left(\tilde{u}_{j}^{\prime}\right)$, (Levy 1959). In addition, advertising can alter the evaluative search cost of inclusion of an online firm in the consideration set, $s_{j}$, as well as the disutility of shopping experience cost, $d_{j}$. Non-advertising information provided by the firm may also increase, or decrease, the information evaluation and processing costs of the consumer.

Theories of consumer behavior can be examined empirically in several ways. The approach we use in this paper is an aggregate analysis across a large body of online consumers. We examine several aggregate implications of our theory. We aim our analysis at the formation of the consideration set online, as well as the decision to purchase, given the consideration set size. In doing so, we base our empirical analysis off of equation 1.5. We assume various constructs contribute to the consideration costs, disutility of experience cost, as well as the size of the consideration set. In addition, we assume that the elements that contribute to the search cost are the same elements that potentially contribute to the disutility of experience cost, but that the consumer experiences them at different stages in the purchasing decision. The assumptions are expressed below in equation 1.5 and 1.6:

$$
\begin{aligned}
& s_{j}=f\left(\text { AbundandAds }_{j}, \text { Information Overload }_{j}, \text { Poor Ease of Use } e_{j}\right) \\
& d_{j}=f\left(\text { AbundantAds }_{j},\right. \text { Information Overload } \\
& \text {, Poor Ease of Use } \left.e_{j}\right)
\end{aligned}
$$

If the consumer decides to purchase from their given consideration set of firms, we assume that the utility derived from the online experience outweighed the cost, as shown in equation 1.2. In addition, we examine the average benefit to cost ratio across all firms by examining consumer conversion rate, or rather the number of unique purchases made by a consumer divided by the number of unique online firm visits. We assume that the greater the number of purchases relative to number of visits, the greater the utility derived from their online experience. We therefore estimate a three-stage model, where in the first stage consumers form their consideration set. In the second stage of the model, consumers choose whether to purchase from the given consideration set of firms or not. Then finally, in the third stage, consumer conversion rate is examined, or the likelihood of consumers to purchase multiple times given the number of firms in their consideration set. Conversion rate is examined as a function of costs, assessed through negative firm features, consideration set size, customer heterogeneity, and variance of products being searched for.

\section{Data and Measurement}

\section{Data Collection}

This study performs a fresh analysis of secondary data. The secondary data is from a field survey that was distributed in June 2002 to a group of randomly selected online consumers, from preexisting consumer panels. The preexisting online consumer panel is composed of nearly 600,000 individuals who have agreed to participate in our surveys and provide information on their 
purchasing. In addition to survey responses, panel information includes demographics information. A total of 2551 individuals responded to the survey. Respondents received an e-mail invitation to participate in the survey with an attached URL linked to the Web-based survey form. The sample is fully applicable to the US online population within a 3\% confidence interval. The research partner conducted appropriate pre-tests and pilot samples before administering the survey to the general online consumer pool. The research partner is one of the largest market research companies in the US, and maintains a general research panel of 400,000 households. Non-response bias was tested for using age, gender, income, education, online tenure and connection speed. No significant non-response bias was detected.

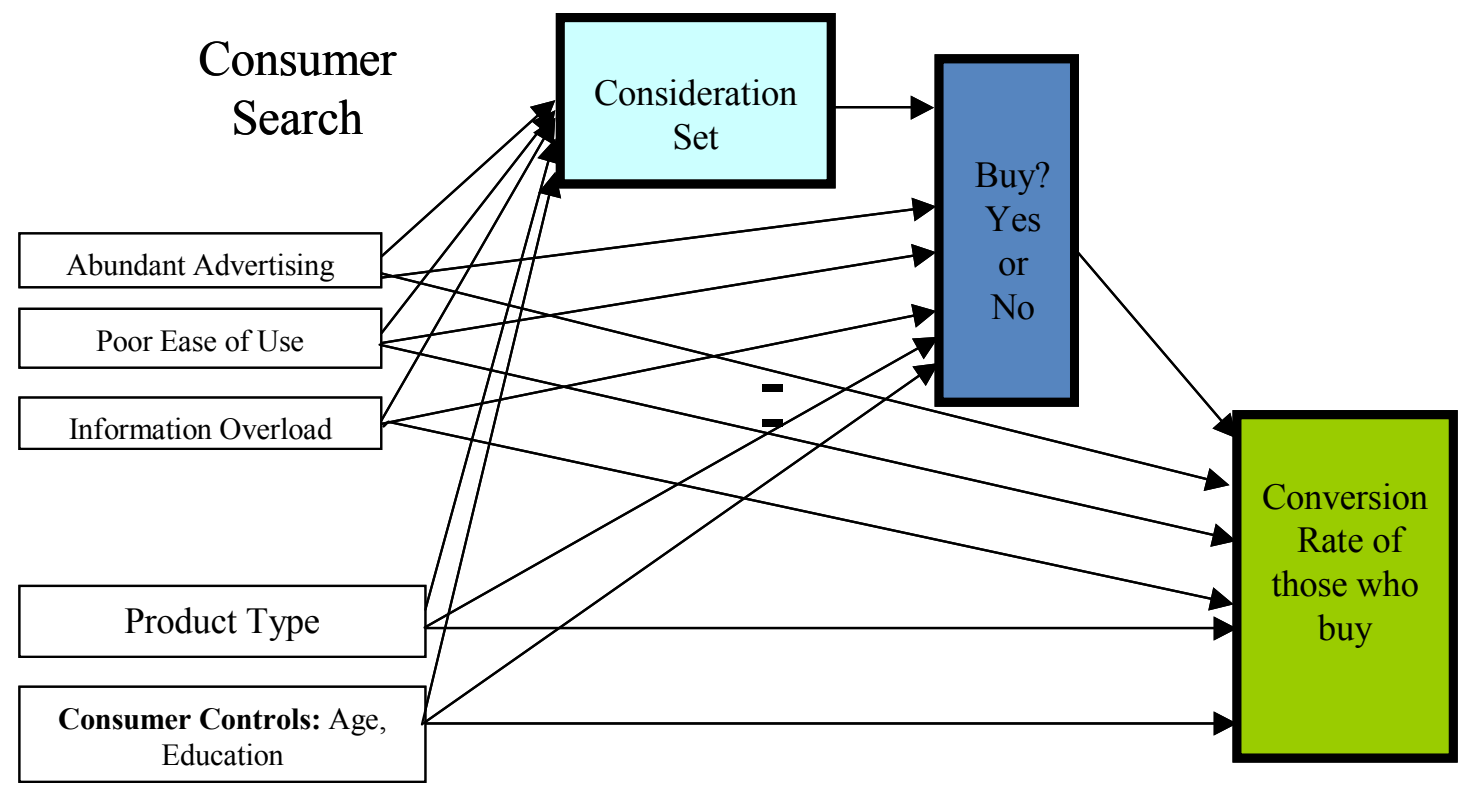

Figure 1. Research Model

\section{Survey Style}

The majority of questions in the survey were asked in a binary manner. Consumer were asked to answer 'yes' or 'no' as to whether they had visited each of the 25 sites in the sample, and to whether they had bought from each of the 25 sites in the sample. Of the 25 online retailers that were examined, seven were considered to be market leaders. The assessment of market leaders was based on the number of external firms that linked to that firm's WebPages. Firms significantly above the mean across all firms were considered market leaders, firm significantly below the mean were considered market followers. Previous work has also used links to a firm's website as a proxy for market power (e.g. Smith and Brynjolfsson, 2001).

Consumers were also given a list 15 items they may have encountered when searching for firms, or when partaking in a firm's shopping experience. Consumers were asked to answer 'yes' or 'no' as to whether they had experienced any of these items. These items were then factor analyzed in order to assess the impact of aggregate experience factors theorized to be of impact.

\section{Factor Analysis}

A total sample of 2551 consumer observations was examined. In order to measure elements of the decision-to-purchase cost, as aligned with theory, three factors were utilized. These factors were based on the categories of: information, advertising, and ease of use. The data was examined using principal component analysis as the extraction technique. Fifteen items were factoranalyzed using a varimax rotation. The goal of the factor analysis was to extract independent attributes that aligned with theory and detracted from the online consumer experience. Following an approach used by previous researchers, we dropped items with multiple loadings across factors during the iterations of the factor analysis, or with a loading of less than 0.30 (Doll and 
Torkzadeh, 1988). Thirteen items loaded unambiguously on three factors; these results are shown in Table 2. These factors were interpreted as Poor Ease of Use, Abundant Advertising, and Information Overload.

Reliability of the overall scale, as well as the individual factors, exceeded the accepted threshold of 0.60 (Nunally 1967). The 13-item scale had an overall reliability of 0.74 . The reliability of each factor was: 0.69 for Poor Ease of Use, 0.67 for Abundant Advertising, and 0.60 for Information Overload.

Table 1. Factor Analysis

\begin{tabular}{|l|c|c|c|}
\hline & Poor Ease of Use & $\begin{array}{c}\text { Abundant } \\
\text { Advertising }\end{array}$ & $\begin{array}{c}\text { Information Overload } \\
\text { (requested and presented) }\end{array}$ \\
\hline Poor site search (no relevant results) & $\mathbf{0 . 4 4 9 7 5}$ & 0.12398 & 0.15000 \\
\hline Out-of-date content (faqs, offers, etc.) & $\mathbf{0 . 0 4 8 3 6}$ & 0.14620 & 0.10843 \\
\hline Broken links & $\mathbf{0 . 4 1 9 5 6}$ & 0.20067 & 0.07929 \\
\hline Mislabeled links & $\mathbf{0 . 4 1 4 1 8}$ & 0.14757 & 0.20152 \\
\hline Unclear how to contact the company & $\mathbf{0 . 3 6 7 8 9}$ & 0.13790 & 0.19153 \\
\hline Unclear site map & $\mathbf{0 . 3 6 5 3 4}$ & 0.04903 & 0.26132 \\
\hline $\begin{array}{l}\text { Hard-to-use functionality for interactive } \\
\text { tools (product config., wish list, etc.) }\end{array}$ & $\mathbf{0 . 3 6 3 0 6}$ & 0.06623 & 0.28541 \\
\hline Many ad banners & 0.12544 & $\mathbf{0 . 5 2 8 8 9}$ & 0.11985 \\
\hline Many pop-up ads & 0.10287 & $\mathbf{0 . 5 1 8 7 1}$ & 0.05151 \\
\hline Lengthy/complicated check-out process & 0.17953 & 0.14540 & $\mathbf{0 . 3 8 7 4 0}$ \\
\hline Too many links on a page & 0.12396 & 0.09458 & $\mathbf{0 . 3 8 3 8 4}$ \\
\hline Long, scrolling pages & 0.19622 & 0.10754 & $\mathbf{0 . 3 7 9 0 0}$ \\
\hline $\begin{array}{l}\text { Lengthy/complicated registration and/or } \\
\text { log-in process }\end{array}$ & 0.17583 & 0.13810 & $\mathbf{0 . 3 7 2 7 0}$ \\
\hline
\end{tabular}

\section{Variables Definition in Empirical Model}

The following variables were used in our analysis:

Poor Ease of Use: As shown in Table 1, the Poor Ease of Use construct of an online experience is measured using seven separate items: (1) Poor site search (no relevant results); (2) Out-of-date content (faqs, offers, etc.); (3) Broken Links; (4) Mislabeled Links; (5) Unclear how to contact company; (6) Unclear Site Map; and (7) Hard-to-use functionality for interactive tools (product config., wish list, etc.). Consumers were asked to select all items they had encountered when shopping online. The items were worded exactly as above. Usability is, in essence, the ease consumers have of navigating through, and purchasing from a given site. Thus, while it is important for a site to be dynamic, if interaction of a site comes at the cost of poor ease of use, buyer experience may suffer. For the final Poor Ease of Use score, a sum was taken across the binary items that loaded unto the Poor Ease of Use factor. The reliability index of 0.69 for this measure was well above the threshold recommended by Nunnally (1967).

Abundant Advertising: The Abundant Advertising factor measures the amount of adveritisng the consumer has seen in their online shopping experience relative to individual limitations. The factor is measured using two items: (1) Many ad-banners; and (2) Many pop-up ads. The final score of each consumer's Abundant Adveritising experience obtained by summing the two binary items. The reliability index of 0.69 for this measure was also well above the threshold recommended by Nunnally (1967).

Information Overload: The Information Overload factor measures the amount of raw information, provided by the firm and elicited from the consumer. Previous research suggests increased raw information is negatively associated with price premium charged by online retailers (Farag and Krishnan, 2002a). Thus, this factor attempts to assess the impact of information overload on buyer conversion rate. The factor is measured using four separete items: (1) Lengthy/complicated check-out process; (2) Too many links on a page; (3) Long, scrolling pages; and (4) Lengthy/complicated registration and/or log-in process. The overall Information Overload score is a sum across the individual binary items that loaded onto the factor. The reliability index of 0.60 for this measure is just at the threshold recommended by Nunnally (1967). 


\section{Control Variables}

Age and Education: Age and Education are two separate, categorical variables that assess the age group, and education level that the consumer lies within. Such demographic variables are controlled for in order to minimize difference across online buying propensity that is based on consumer background, rather than consumer online experience.

Number of Products: The utility of the shopping experience will likely vary based upon the number of goods of different types being shopped for. The conceptual model assumes a fixed product being shopped for, thus we address this issue by controlling for the number of products being shopped for. The consumers were asked how many different products they had shopped for online in the past month. We control for such an amount as a means of assessing breadth of search.

\section{Dependent Variables}

Consideration Set: The consideration set is an assessment of the number of firms a consumer visited over a given period online buying. The consideration set is assessed as the total number of unique firms visited.

Buy/No Buy: This second stage dependent variable is just a binary assessment of whether the consumer made any purchases or not.

Conversion Rate: Conversion rate assess the propensity of a consumer to buy from a firm that he or she has visited. If a firm reaps positive value from an online shopping experience their propensity to buy from that firm should be higher. Conversion Rate is calculated as the number of unique purchases divided by the number of unique visits to an online retailer. We assess the aggregate conversion rate, across all retailers.

\section{Analysis and Results}

\section{Model Specification}

The model is based off of our theory of consideration sets and the costs involved in the purchase decision, including search costs and decision costs. The equations associated with the 3 -stages of the model are therefore as follows:

\section{Stage 1:}

(Consideration Set) $=\alpha_{1}+\alpha_{2} *$ (Poor Ease of Use $)+\alpha_{3}^{*}($ Abundant Advertising $)+\alpha_{4} *$ (Information Overload $)+\alpha_{5} *$ (Number of Products) $+\alpha_{6} *$ (Age) $+\alpha_{7}^{*}$ (Education) $+\epsilon_{1}(2)$

\section{Stage 2:}

(Buy/Not Buy $)=\alpha_{1}+\alpha_{2} *($ Consideration Set $)+\alpha_{3} *($ Poor Ease of Use $)+\alpha_{4} *($ Abundant Advertising $)+\alpha_{5}^{*}($ Information Overload $)+\alpha_{6} *($ Number of Products $)+\alpha_{7} *($ Age $)+\alpha_{7} *$ (Education $)+\epsilon_{1}$ (2)

Stage 3:

$($ Conversion Rate $)=\alpha_{1}+\alpha_{2} *($ Consideration Set $)+\alpha_{3} *($ Poor Ease of Use $)+\alpha_{4} *($ Abundant Advertising $)+\alpha_{5} *($ Information Overload $)+\alpha_{6} *$ (Age) $+\alpha_{7}^{*}$ (Education) $+\alpha_{8}^{*}($ Type of Good $)+\epsilon_{1}$ (3)

\section{Estimation Procedures}

For the consideration set model and the aggregated conversion rate model the dependent variables are continuous and therefore the model parameters were estimated using ordinary least squares ("OLS"). For the decision to Buy model, stage 2, the dependent variable is binary, thus we estimated it using a Probit model, so that the estimates would be more efficient, and so that we control for independence of irrelevant alternatives. Multicollinearity refers to significant correlations among the independent variables. In our model, it may be argued that independent variables such as number of visits and number of products browsed may be correlated. Hence, it is important to test for any significant multicollinearity effects on the parameters in our models. The effect of multicollinearity in the above model was evaluated by computing the Variance Inflation Factor ("VIF"), as well as the condition number. The mean VIF for the models in our analysis ranged from 1.10 to 1.62, and the highest condition numbers ranged from 
1.79 to 3.68; indicating no significant effect of multicollinearity on parameter estimates. The resulting parameter estimates of the models are shown in Tables 2 and 3. The calculated values of F-statistics for the models exceeded the critical values at the $5 \%$ significance level, indicating that our models explain a significant portion of the variance in conversion rate, visiting, and buying.

\section{Discussion and Results}

\section{Results}

The results of stage 1 of the model, consideration set formation, are shown in Table 2. We see that two significant firm factors are associated with consumer consideration set size; these are poor ease of use and abundant advertising. Interestingly, both are positively associated with consideration set size. A positive association means that the more a consumer experienced poor ease of use, the larger the size of his consideration set. Similarly for abundant advertising, the more a consumer experienced abundant levels of advertising, the larger the consideration set of the consumer. The positive association of poor ease of use to consideration set size is likely due to consumers being dissatisfied with the shopping experience at a given sight, and therefore choosing to examine another site in search of a simpler interface. The positive sign of abundant advertising could be interpreted in several ways. If the consumer experienced abundant advertising at a given site, it may have been perceived as a nuisance to their shopping experience, thus driving the consumer to switch online firms, or consider a different firm where there is not advertising on the site (Amazon.com for example has no advertising). Alternatively, consumers may have experienced many popup ads at competitor sites for a given firm, and chosen to follow that advertisement to another firm. In this case, the advertisements were not seen as a nuisance, but rather as potential decrease in search cost, as it may have helped the consumer locate their given product with less consideration costs. Another interesting result of the consideration set is that age and education have opposing associations with consideration set size. Thus, more educated individuals have larger consideration sets, when controlling for age. Older people, on the other hand, are associated with smaller consideration sets, when controlling for education. This result may suggest that education drives consumers to search out a greater breadth of firms, whereas increased age is associated with less information-processing time, and thus smaller consideration sets.

Table 2. Consumer Consideration Set

\begin{tabular}{|c|c|}
\hline \multicolumn{2}{|c|}{ Number of Firms in a Consumer Consideration Set } \\
\hline Variable & $\begin{array}{c}\text { All Consumers } \\
(\mathbf{n}=\mathbf{2 5 5 1})\end{array}$ \\
\hline Poor Ease of Use & $\mathbf{0 . 2 3 0 5} * *$ \\
& $\mathbf{( 5 . 1 6 )}$ \\
\hline Abundant Advertising & $\mathbf{0 . 2 6 6 2 * *}$ \\
& $\mathbf{( 3 . 1 4 )}$ \\
\hline Information Overload & -0.0568 \\
& $(-0.82)$ \\
\hline Number of Products & $0.3926^{* *}$ \\
& $(18.33)$ \\
\hline Age & $-0.0419^{*}$ \\
& $(-1.88)$ \\
\hline Education & $0.312^{* *}$ \\
& $(5.03)$ \\
\hline Adj. $\mathbf{R}^{\mathbf{2}}$ & 0.1788 \\
\hline F-Stat & 93.53 \\
Prob $>$ F & $(\mathrm{p}<0.000)$ \\
\hline
\end{tabular}

In stage 2 and 3 of the model we examine the consumer purchase decision, and conversion rate of consumers who purchase. We see from Table 3, that in the aggregate, across all firms, poor ease of use is negatively associated with buyer conversion rate. In addition, the decision to purchase, is associated with the size of the consideration set, but is irrespective of the characteristics of the firm. Unlike stage 1 of the model, Age in stage 2 of the model is positively associated with likelihood to purchase. Thus, 
older consumers are more likely to purchase. In addition, the number of products is negatively associated with likelihood to purchase. Stage three of the model has similar results to stage 2 of the model; with the exception that abundant advertising has a significant, negative association with buyer conversion rate.

Table 3. Stage 2 and 3 - Purchase Decision and Aggregate Consumer Conversion Rate

\begin{tabular}{|c|c|c|c|}
\hline \multirow[b]{2}{*}{ Variable } & \multirow{2}{*}{$\begin{array}{c}\text { Purchase Decision } \\
\text { Buy/Not Buy }\end{array}$} & \multicolumn{2}{|c|}{$\begin{array}{c}\text { Consumer Conversion Rate } \\
\text { (Number of Purchases/Number of Visits) }\end{array}$} \\
\hline & & $\begin{array}{c}\text { OLS Estimates } \\
\text { (Online Consumers Who Made } \\
\text { a Purchase) }\end{array}$ & $\begin{array}{c}\text { SURE Estimates } \\
\text { (Online Consumers Who } \\
\text { Made a Purchase) }\end{array}$ \\
\hline Poor Ease of Use & $\begin{array}{l}0.0059 \\
(0.32)\end{array}$ & $\begin{array}{c}-0.0006 \\
(-0.15)\end{array}$ & $\begin{array}{c}-0.0006 \\
(-0.14)\end{array}$ \\
\hline Abundant Advertising & $\begin{array}{l}0.0006 \\
(0.02)\end{array}$ & $\begin{array}{l}-0.0167 * \\
(-1.79)\end{array}$ & $\begin{array}{l}-0.0167^{*} \\
(-1.79)\end{array}$ \\
\hline Information Overload & $\begin{array}{c}-0.0136 \\
(-0.47)\end{array}$ & $\begin{array}{l}0.0015 \\
(0.21)\end{array}$ & $\begin{array}{l}0.0015 \\
(0.21)\end{array}$ \\
\hline Number of Products & $\begin{array}{c}-0.0247^{* *} \\
(-2.29)\end{array}$ & $\begin{array}{l}-0.0054 * * \\
(2.29)\end{array}$ & $\begin{array}{l}-0.0054 * * \\
(2.29)\end{array}$ \\
\hline Consideration Set & $\begin{array}{c}0.0382 * * \\
(4.57)\end{array}$ & $\begin{array}{l}-0.0411 * * \\
(-19.46)\end{array}$ & $\begin{array}{l}-0.0411 * * \\
(-19.67)\end{array}$ \\
\hline Age & $\begin{array}{c}0.0324 * * \\
(3.58)\end{array}$ & $\begin{array}{l}0.0034 \\
(1.39) \\
\end{array}$ & $\begin{array}{l}0.0034 \\
(1.39) \\
\end{array}$ \\
\hline Education & $\begin{array}{c}0.1586 * * \\
(6.22) \\
\end{array}$ & $\begin{array}{c}\mathbf{0 . 0 2 2 1} * * \\
(3.00)\end{array}$ & $\begin{array}{c}0.0221 * * \\
(3.00)\end{array}$ \\
\hline Adj. $\mathbf{R}^{2} /$ "R $\mathbf{R}^{2}$ ' & 0.0244 & 0.2934 & 0.2967 \\
\hline $\begin{array}{c}\text { LR(ChiSq) } / \text { F-Stat } \\
\text { Prob }>\text { ChiSq } / \text { Prob }>\text { F }\end{array}$ & $\begin{array}{c}82.32 \\
(\mathrm{p}<0.000)\end{array}$ & $\begin{array}{c}63.81 \\
(\mathrm{p}<0.000)\end{array}$ & $\begin{array}{c}510.86 \\
(p<0.000)\end{array}$ \\
\hline
\end{tabular}

Next we split the sample into market leaders and market followers, and examine how consideration set effects market leaders versus market followers in order to assess the differing effects of consumer searching on differing types of companies.

\section{Results for Market Leaders and Market Followers}

In splitting the sample between market leaders and market followers we are interested in contrasting the effects of consumer consideration sets and firm experience factors on consumer likelihood to purchase, stage 2, and buyer conversion rate, stage 3 . In order to more fully understand consideration set impacts, we split the general consideration set into the set of market leaders the consumer searched for (consideration set of leaders) and the set of market followers the consumer searched for (consideration set of followers); the results are shown in Table 4. Perhaps the most interesting result from stage 2 of the model is that while both follower and leader consideration sets are positively associated with propensity to buy from a market follower, follower consideration sets are negatively associated with propensity to buy from a market leader. This result makes sense, as most consumers are aware of market leaders, thus they may go to Amazon.com for example, read the book reviews, and then purchase a book from a cheaper, follower site. However, many consumers are not aware of market followers, as market leaders have such a strong presence. Thus, those consumers who are aware of the market followers, and include them in their consideration set are less likely to purchase from market leaders. Another interesting result is the significant, negative association of poor ease of use to propensity to purchase from a market leader. Poor ease of use is not significant in the case of market followers. These results suggest that market leaders are expected to have an easy to use site so that consumers will want to return to partake in the shopping experience again. 
Table 4. Market Leaders, Market Followers: Consumer Consideration Set Stage 2 and 3 - Purchase Decision and Aggregate Consumer Conversion Rate

\begin{tabular}{|c|c|c|c|c|}
\hline \multirow[b]{2}{*}{ Variable } & \multicolumn{2}{|c|}{$\begin{array}{c}\text { Purchase Decision } \\
\text { Buy/Not Buy }\end{array}$} & \multicolumn{2}{|c|}{$\begin{array}{c}\text { Consumer Conversion Rate } \\
\text { (Number of Purchases/Number of Visits) }\end{array}$} \\
\hline & $\begin{array}{l}\text { Market } \\
\text { Leaders }\end{array}$ & $\begin{array}{c}\text { Market } \\
\text { Followers }\end{array}$ & Market Leaders & Market Followers \\
\hline Poor Ease of Use & $\begin{array}{c}-0.0326 * \\
(-1.82)\end{array}$ & $\begin{array}{c}0.0204 \\
(0.95) \\
\end{array}$ & $\begin{array}{l}0.0017 \\
(0.33) \\
\end{array}$ & $\begin{array}{r}-0.0011 \\
(-0.17) \\
\end{array}$ \\
\hline Abundant Advertising & $\begin{array}{c}0.0002 \\
(0.01) \\
\end{array}$ & $\begin{array}{c}-0.0368 \\
(-0.89)\end{array}$ & $\begin{array}{c}-0.0108 \\
(-1.13)\end{array}$ & $\begin{array}{l}-0.0172 * \\
(-1.71)\end{array}$ \\
\hline Information Overload & $\begin{array}{c}0.0017 \\
(0.05) \\
\end{array}$ & $\begin{array}{l}-0.0034 \\
(-0.10) \\
\end{array}$ & $\begin{array}{l}0.0018 \\
(0.23)\end{array}$ & $\begin{array}{r}0.0109 \\
(1.18) \\
\end{array}$ \\
\hline Number of Products & $\begin{array}{c}\mathbf{0 . 0 1 8 1 *} \\
(1.90)\end{array}$ & $\begin{array}{r}0.0139 \\
(1.36)\end{array}$ & $\begin{array}{l}0.0005 \\
(0.19)\end{array}$ & $\begin{array}{c}0.0014 \\
(0.45)\end{array}$ \\
\hline Consideration Set of Leaders & $\begin{array}{c}0.4338 * * \\
(22.48)\end{array}$ & $\begin{array}{c}0.0677 * * \\
(3.10)\end{array}$ & $\begin{array}{l}-0.1387 * * \\
(-23.28)\end{array}$ & $\begin{array}{r}-0.0066 \\
(-1.01)\end{array}$ \\
\hline Consideration Set of Followers & $\begin{array}{c}-0.0962 * * \\
(-5.53)\end{array}$ & $\begin{array}{l}0.2238 * * \\
(16.56)\end{array}$ & $\begin{array}{c}-0.0024 \\
(-0.81)\end{array}$ & $\begin{array}{c}-0.0728 * * \\
(-17.82)\end{array}$ \\
\hline Age & $\begin{array}{c}\text { 0.01903* } \\
(1.89)\end{array}$ & $\begin{array}{l}0.0036 \\
(0.33)\end{array}$ & $\begin{array}{r}-0.0017 \\
(-0.66)\end{array}$ & $\begin{array}{l}0.0038 \\
(1.18)\end{array}$ \\
\hline Education & $\begin{array}{l}0.0315 \\
(1.13)\end{array}$ & $\begin{array}{l}0.0205 \\
(0.66)\end{array}$ & $\begin{array}{c}-0.0050 \\
(-0.71)\end{array}$ & $\begin{array}{l}0.0107 \\
(1.20)\end{array}$ \\
\hline Adj. $\mathbf{R}^{2}$ / "R" & 0.2134 & 0.1719 & 0.4440 & 0.3830 \\
\hline $\begin{array}{c}\text { LR(ChiSq) } / \text { F-Stat } \\
\text { Prob }>\text { ChiSq } / \text { Prob }>\text { F }\end{array}$ & $\begin{array}{c}731.99 \\
(p<0.000)\end{array}$ & $\begin{array}{c}460.76 \\
(p<0.000)\end{array}$ & $\begin{array}{c}63.81 \\
(\mathrm{p}<0.000)\end{array}$ & $\begin{array}{c}54.69 \\
(\mathrm{p}<0.000)\end{array}$ \\
\hline
\end{tabular}

In stage three of the model, we examine consumer conversion rate of those consumers who made a purchase from either a market leader or market follower. In the case of market leader conversion rate, the only significant factor is the consideration set of leaders. The negative association asserts that as the consideration set of leaders increases, the ratio of leader purchases to leader visits decreases. This result is straight-forwards, as an increase in the leader consideration set is directly related to an increase in the denominator of the conversion rate ratio. Therefore, as the denominator increases, conversion rate decreases. In the case of market follower conversion rate, both abundant advertising and follower consideration set are negative and significant. The result of abundant advertising being significant and negative for market followers, but not for market leaders suggests that market follower consumers are potentially less loyal, and more easily affected by the presence of abundant advertising on a follower site. Alternatively, market leaders may not advertise as much, as they may not find it necessary.

\section{Discussion}

In this paper we advance a three-stage model of assessing online consumer purchase experience. Aligned with prior literature on consumer brand selection, the first stage of the model is consideration set composition. Stage 2 of the model examines the decision to purchase from any of the firms in the consideration set. While firm features, such as poor ease of use and abundant advertising where significantly associated with the size of the consideration set, none of the firm features are significantly associated with the purchase decision in the aggregate analysis. However, poor ease of use was significant and negatively associated with the purchase decision for market leaders only. Thus, if the consumer experience poor ease of use, this is indeed of detriment to market leaders. Market followers, on the other hand, may not be expected to provide the easiest to use interface, but rather just cheaper prices, or more promotions, and thus poor ease of use does not significantly affect the market follower purchase decision. The size of the consideration set is positively associated with the probability that a consumer will purchase in the aggregate analysis. Thus consumers with larger consideration sets are more likely to purchase; this result could indicate that the larger consideration set assures that the consumer found the product and shopping experience they were looking for. An alternative explanation is that consumers who have spent the consideration cost to assemble a large consideration set may be motivated to buy so as to not have to reassemble the consideration set at a later date. The results of the market follower analysis 
are similar to the aggregate analysis, in that consideration set size of leaders and followers is positively associated with the decision to purchase. However, in the case of the decision to purchase from a market leader, an increase size of the market follower consideration set is negatively associated with the decision to purchase from a market leader. Thus, those consumers who are aware of the market followers, and include them in their consideration set are less likely to purchase from market leader. This result suggests that it is in the interest of market leaders to attempt to decrease consumer search through online personalization and other features, as many of them have started to do.

Unlike stage 1 of the model, Age in stage 2 of the model is positively associated with likelihood to purchase. Thus, older consumers are more likely to purchase. This result suggests that older consumers may search less, but purchase more, and thus firms may want to focus on making their site easy to find in order to target older consumers. Similar results are seen in the market leader model, where age is positively associated with likelihood to purchase. However, in the market follower model, age is not significant. An interesting result that differs in the aggregate analysis and the market leader analysis is the effect of the number of products being shopped for. The number of products is negatively associated with likelihood to purchase in the aggregate analysis, however it is positively associated with likelihood to purchase in the market leader model. In the aggregate, one would expect that this result suggests that consumers who search across many products can be classified as "browsers" rather than "buyers" and use online retailing as an information gathering process, rather than a purchasing process. However, in the case of the market leaders, many of these leaders carry a large breadth of products. Thus, if consumers are shopping for many types of products, and the market leader carries most of these types of products, the likelihood that the consumer will purchase from that market leader increases. It is interesting to note that the variance in products being searched for, or the number of products also has a positive association with consideration set size. Thus, while many analysts criticized Amazon.com for covering too vast an array of products, it may work towards their advantage in increasing consumer propensity to buy from them.

Stage three of the model has similar results to stage 2 of the model; with the exception that abundant advertising has a significant, negative association with buyer conversion rate in the aggregate, as well as in the market follower model. This result may suggest that for buyers who purchase from market followers, online advertising is considered a nuisance that detracts from further purchases. Thus, firms should be careful in utilizing online advertising; while advertising may be beneficial towards consumers including a firm in their consideration set, as we saw in stage 1 of the model, if too much advertising is implemented, it may then deter consumers from making further purchases. Alternatively, market leaders may just not advertise as much, as they may not find it necessary. Amazon.com, for example, recently announced that they would discontinue all advertising, as they perceive that their brand recognition is sufficiently strong (New York Times).

\section{Conclusion}

In this paper, we executed a detailed econometric analysis of negative experience factors, consideration set formation, and buyer conversion rate online. Through comprehensive use of an empirical framework, we explore consumer search behavior and firm experience heterogeneity. Within this framework, we show that different types experience contrasting effects of consumer consideration sets. For market leaders, a larger consideration set of market followers is associated with a decrease in propensity to buy from market leaders. Thus, market leaders must strive to improve the "stickiness" of their site through online customer service features, such as personalization. This is further evidenced by the significant negative correlation of poor ease of use with propensity to buy from market leaders. Consumers expect market leaders to have an easy to use, value-adding shopping experience. Such an expectation does not seem to exist for market followers. In addition, the effects of online advertising are still unclear; on the one hand abundant advertising is associated with a larger consideration set, and therefore may encourage consumers to consider firms they may not have other wise considered, and may also consider firm to may a purchase. On the other hand, abundant advertising is associated with lower conversion rate of customers for market followers, suggesting that there can, indeed, be too much of a good thing. While market followers may use abundant advertising to attempt to build their market presence, they must be aware that such advertising has a negative impact that is significant for them, but not for market leaders. Thus, market followers should not necessarily just "follow the leader", as a backlash may result. This study has taken a first step towards illuminate how strategies for market leaders and market followers online contrast. More market leaders, careful implementation of online service factors may potentially allow them to increase loyalty, and therefore decrease consumer searching. However, for followers, consumer searching across other followers, as well as across leaders is not necessarily detrimental; thus follower firms may want to put direct comparisons on their site to leader firms in order to boost their market power. Through careful implementation of differing strategies, firms may turn their online retail ventures into entities of significant market power, where profitability exists around the corner, despite the perceived extinction of the dot-com boom. However, firms must be careful not push the online service features to the point where they are poorly implemented, as customer loyalty will suffer. 


\section{References}

Alba, Joseph, and Chattopadhyay, Amitava (1985). "Effects of Context and Post-Category Cues on Recall of Competing Brands." Journal of Marketing Research 22(August): 340-349.

Alba, Joseph, Lynch, John, Weitz, Barton, Janiszewski, Chris, Lutz, Richard, Sawyer, Alan, and, Wood, Stacy (1997). "Interactive Home Shopping: Incentives for Consumers, Retailers, and Manufacturers to participate in electronic marketplaces.” Journal of Marketing 61(July): 38-53.

Anders, George (1998). "Cybersqueeze: Comparison shopping is the Web's virtue-- unless you're a seller." Wall Street Journal July 23(A1).

Anders, George (1999). “Web seller asks: how low can PC prices go?” Wall Street Journal January 19.

Bakos, J.Yannis (1997). "Reducing Buyer Search Costs: Implication for Electronic Marketplaces." Management Science 43(12).

Belonax, Joseph A., and Mittelstaedt, Robert A. (1978). Evoked Set Size as a Function of Number of Choice Criterion and Information Variability. Advances in Consumer Research. H. K. Hunt. Ann Arbor, MI, Association for Consumer Research. 5: $48-51$.

Brynjolfsson, Erik, and Smith, Michael; and (2000). "Frictionless Commerce? A Comparison of Internet and Conventional Retailers.” Management Science 46(4): 563-585.

Dewan, Rajiv, Freimer, Marshall, and Zhang, Jie (2002). Managing web site for profitability: Balancing content and advertising. Hawaii International Conference on Systems Sciences, Kona, Hawaii.

Fader, Peter S.; Hardie, Bruce G. (1999). "Forecasting Repeat Sales at CDNOW: A Case Study." Working Paper, The Wharton School of the University of Pennsylvania.

Farag, Neveen I., and Krishnan. M.S. (2002a) "Price Dispersion and Online Information: Quality or Quantity? " UMBS Working Paper, 2002.

Farag, Neveen I., and Van Alstyne, M. (2002b) “An Analytical Examination of Online Personalization and Price” UMBS Working Paper.

Hauser, John R. and Wernerfelt, Birger (1990). "An Evaluation Cost Model of Consideration Sets.” Journal of Consumer Research 16(4): 393-408.

Hoffman, D., Novak, T., and Chatterjee, P. (1995). "Commercial Scenarios for the Web: Opportunities and Challenges." Journal of Computer Mediated Communication 1(3): <www.ascusc.org/jcmc/voll/issue3/hoffman.html.

Howard, John A. and Sheth, Jagdish N. (1969). The Theory of Buyer Behavior. New York, John Wiley.

Iyengar, Sheena and Lepper, Mark R. (2000), -- "When Choice Is Demotivating: Can One Desire Too Much Of A Good Thing?" Journal Of Personality And Social Psychology, 76, 995-1006.

Levy, Sidney (1959). “Symbols for Sale.” Harvard Business Review 4(July/August): 117-124.

Manrai, A.K. and Andrews, R.L. (1998). "Two-stage discrete choice models for scanner panel data: An assessment of process and assumptions." European Journal of Operations 111(20): 193-215.

McLaughlin, Laurianne (2002). The Straight Story on Search Engines. PC World. July.

Mehta, N., Rajiv, S., and Srinivasan, Kannan (2003). "Price Uncertainty and Consumer Search: A Structural Model of Consideration Set Formation.” Journal of Marketing 22(1): 58-84.

Meyer, Robert (1979). “Theory of Destination Choice Set Formulation Under Informational Constraint." Transportation Research Record 750: 6-12.

Miller, George A. (1956). "The Magical Number Seven, Plus or Minus Two: Some Limitations on Our Capacity For Processing Information." The Psychology Review 63: 81-97.

Nelson, Phillip (1970). "Information and Consumer Behavior." Journal of Political Economy 78(March/April): 311-329.

Payne, John W. (1982). “Contingent Decision Behavior.” Psychological Bulletin 92(2): 382-402.

Pazgal, Amit, and Vulcan, Nir (1998). Have your agent call mine: software agents, the Internet and marketing. Cambridge, MA, INFORMS Mini-Conference, MIT Sloan School.

Quick, Rebecca (1998). “Web's robot shoppers don't roam free.” Wall Street Journal September 3(B-1, B-8).

Richardson, Anthony (1982). "Search Models and Choice Set Generation." Transportation Research 16A(5-6): 403-420.

Schmalansee, Richard (1982). "Product Differentiation Advantages to Pioneering Brands." American Economic Review 72(June): 159-180.

Silk, Alvin J. and Urban, Glen L. (1978). "Pre-Test Market Evaluations of New Packaged Goods: A Model and Measurement Methodology." Journal of Marketing Research 15(May): 171-191.

Smith, Michael D., Joseph Bailey, Erik Brynjolfsson. (2000). Understanding Digital Markets: Review and Assessment, Brynjolfsson and Kahin eds. Understanding the Digital Economy, MIT Press, Cambridge, MA, 99-136.

Smith, Michael, Erik Brynjolfsson. 2001. Customer Decision Making at an Internet Shopbot: Brand Still Matters. The Journal of Industrial Economics 49(4) 541-558.

Stigler, George J. (1961). “The Economics of Information.” Journal of Political Economy 69(June): 213-225.

Wright, Peter (1975). "Consumer Choice Strategies: Simplifying vs. Optimizing.” Journal of Marketing Research 12(February): 60-67. 